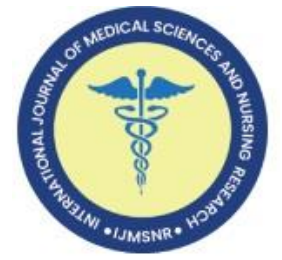

\title{
Determination of Hazard State of Non-Communicable Diseases Using Semi-Markov Model
}

\author{
Balasubramaniam Ramakrishnan ${ }^{1}$, Senthamarai Kannan Kaliyaperumal ${ }^{2}$ (D) Mahalakshmi Rajendran ${ }^{3}$
}

${ }^{1,3}$ Research Scholar, Department of Statistics, Manonmaniam Sundaranar University, Abishekapatti, Tirunelveli, Tamil Nadu, India. ${ }^{2}$ Professor of Statistics, Department of Statistics, Manonmaniam Sundaranar University, Abishekapatti, Tirunelveli, Tamil Nadu, India.

\begin{tabular}{l} 
Abstract \\
\hline \hline $\begin{array}{l}\text { Background: The developed Semi-Markov model with Kumaraswamy Exponentiated Inverse Rayleigh distribution examined patients with } \\
\text { hypertension, heart diseases, smoking habits and Stroke, is measured from one state to another. }\end{array}$
\end{tabular}

Materials and Methods: Patients with Non-Communicable disease described through Kumaraswamy Exponentiated Inverse Rayleigh distribution.

Results: The estimated parameters of Semi-Markov model with this distribution predicted by the maximum likelihood estimation for each successive state observed significant abnormality. The data noted predicts established model is a good fit for many attributes that prevailed in studied data. The developed Semi-Markov model is a best fit for non-Communicable disease in the long run of patient's data. Through different Exponential family distribution, one can look at for further perfect fit of patient data, which is to be estimated.

Conclusion: This model can be an alternative method to estimate the effect of patient in survival analysis, where it will be effective in time consumption in medical field.

Keywords: heart diseases, hypertension, Semi-Markov processes, smoking, stroke

Article Summary: Submitted:11-October-2021 Revised:13-November-2021 Accepted:24-December-2021 Published:31-December-2021

\begin{tabular}{|c|c|c|}
\hline \multirow{3}{*}{ Quick Response Code: } & \multirow{3}{*}{$\begin{array}{c}\text { Web Site } \\
\text { http://ijmsnr.com/ }\end{array}$} & \multirow[b]{2}{*}{$\begin{array}{l}\text { This is an open access journal, and articles are distributed under the terms of the } \\
\text { Creative Commons Attribution-Non-Commercial-ShareAlike } 4.0 \text { International } \\
\text { License, which allows others to remix, tweak, and build upon the work } \\
\text { non-commercially, as long as appropriate credit is given and the new creations } \\
\text { are licensed under the identical terms. }\end{array}$} \\
\hline & & \\
\hline & & $\begin{array}{r}\text { Corresponding Author: Mr. Balasubramaniam Ramakrishnan, } \\
\text { Research Scholar, Department of Statistics, Manonmaniam } \\
\text { Sundaranar University, Abishekapatti, Tirunelveli, Tamil Nadu, India. } \\
\text { Email ID: bala.rcbe@gmail.com }\end{array}$ \\
\hline
\end{tabular}

\section{Introduction}

The World Health Organization (WHO) has predicted that Non-Communicable Diseases (NCDs) get about 40 million individuals worldwide each year [1]. Four major syndromes, the essential focus of worldwide NCDs response has been; cancer, chronic respiratory infections, diabetes and heart disease. The NCDs response also concentrates on four key risk issues; harmful practice of liquor, physical lethargy, tobacco usage and unhealthy diet are the issues perceived by the WHO as significant elements leading to NCDs. In this article, through Semi-Markov Process (SMP) the four major NCDs are depicted with real-life data to find out the survival probability of patients.

Stroke in the human body immune system reveals the identical manner as a heart disease, but this stroke happens in brain (blood flow gets interrupted) which lead to damage. Worldwide, heart diseases cause approximately one third deaths [2]. 15 million people worldwide suffer from stroke each year, with the amount of stroke deaths increases every year [3]. This stroke could even raise for the next upcoming 20 years, specifically in the developing countries [4]. Examining effectiveness in human body and health fitness is an urgent proposal to lesser the burden. Hypertension is a leading risk factor for cardiovascular disease, and randomized cases have determined that antihypertensive drug therapy reduces risks of stroke, cardiovascular disease, heart failure and total mortality [5].

How to cite this article: Ramakrishnan B, Kaliyaperumal SK, Rajendran M. Determination of Hazard State of NonCommunicable Diseases Using Semi-Markov Model. Int J Med Sci and Nurs Res 2021;1(2):23-28 
Some experimental investigations have showed that relationship of blood pressure to cardiovascular risk is not linear, with no better devaluation in risk or perhaps indeed an extended risk identified with low blood pressure.

Getting blood pressure control (BP) in victims with hypertension reduces the risk of stroke and ischemic heart disease [6, 7, 8]. Barriers to hypertension control take place at the stages of the patient, physician and health system, and comprise inadequate approach to high-quality care, physician and patient unwillingness to enhance therapy for uncontrollable BP (i.e., inertia), and treatment non-adherence [9]. The relative influence of these various obstacles is recognized and is not focused on by Joint national committee [10]. The increased incidence of hypertension is due to a combination of behavioral risk factors, age, and population expansion, including recurrent stress, being overweight, a lack of physical activity, hazardous alcohol use, and an unhealthful diet [11].

\section{Materials and Methods:}

\section{Semi - Markov Model:}

This methodology used for the study are elucidated as follows. In Stochastic process, the theory of Semi-Markov Model (SMP) is an area which develops rapidly in the past few decades. The fact is that SMP provide a natural useful model in real life systems of examining, standby systems, stochastic mechanisms and many others. P. Levy the author who individually and instantaneously introduced the $\mathrm{SMP}^{10}$. Derivation of SMP starts from the Markov renewal process with special case of 2dimensional Markov sequence. SMP concept is a normal derivation from the Markov chains [12].

A standardized regular Markov chain, with discrete set of states denotes; $E=0,1,2,3 \ldots$ is simplified by a matrix $Q=q_{i j} ; i, j \in E$ where;

$$
q_{i j}=-q_{i}=-\sum_{j \in E, i \neq j} q_{i j}
$$

Markov chain derives; the $i^{\text {th }}$ state of a particular system having a random time $\theta_{i}$ distributed by the exponential family law with, parameter $q_{i}$ and by the system passing the $j^{\text {th }}$ state with a probability $p_{i j}=\frac{q_{i j}}{q_{i}} i, j \in E$.

The methods and designing of transition probabilities of SMP defined as: Firstly, considering a model with $k$ states belonging to finite state space $E=\{1,2, \ldots, k\}$; where, $\left(X_{0}, X_{1}, X_{2}, \ldots, X_{n}\right) \in E ; \quad$ be the sequential states where the $n$ visits a random process, when $\left(0=T_{0}<\right.$ $\left.T_{1}<\ldots<T_{n}\right)$ are the sequential time to enter into each of these five states. Therefore, the probability of $n$ transitions from the first state to fifth state, denoted by $i$ to $j$, the model fixed is been defined as in eqn. (1).

$$
P_{i j}=P\left(X_{n+1}=j / X_{n}=i\right)
$$

Transition probability, $P_{i j}$ satisfy the conditions, as $P_{i j} \geq 0$, $\sum P_{i j}=1$ for all $j$. As the Marko process does not deal with the population sizes of region at time of the state transitions the random process, esteems the transition population size of region at

$\left(T_{n+1}-T_{n}\right)$ in a SMP and distribution that satisfies:

$$
Q_{i j}(t)=P\left(X_{n+1}=j, T_{n+1}-T_{n} \leq t / X_{n}=i\right) \ldots \ldots
$$

The Kumaraswamy Exponentiated Inverse Rayleigh (KEIR) [16] probability density function (pdf) of population size of region time in a particular state ' $i$ ' before passing to state ' $j$ ' given in eqn. (2)

$$
\begin{gathered}
f_{i j}(t)=\frac{2 a b \alpha \theta}{x^{3}}\left(e^{-\frac{\theta}{x^{2}}}\right)^{a \alpha}\left[1-\left(e^{-\frac{\theta}{x^{2}}}\right)^{a \alpha}\right]^{(b-1)} \\
x \geq 0 ; a, b, \alpha, \theta>0 \ldots \ldots(3)
\end{gathered}
$$

The cumulative density function (CDF) $F_{i j}(t)$, along with corresponding survival function (SF) eqn. (4); of waiting time in state $i, S_{i}(t)$ observed in eqn. (5)

$$
F_{i j}(t)=1-\left[1-\left(\mathrm{e}^{-\frac{\theta}{\mathrm{x}^{2}}}\right)^{\mathrm{a} \alpha}\right]^{\mathrm{b}}
$$

Where $F_{i j}$ is the historical frequency of transition from state $i$ to statej.

$$
S_{i j}(t)=\left[1-\left(\mathrm{e}^{-\frac{\theta}{\mathrm{x}^{2}}}\right)^{\mathrm{a} \alpha}\right]^{\mathrm{b}}
$$

The parameters of the KEIR distribution are predicted through the maximum likelihood estimation (MLE) method.

Log likelihood function is observed in eqn. (6)

$$
\begin{aligned}
l=n \log (2)+n \log & (a)+n \log (b)+n \log (\alpha)+n \log (\theta) \\
& -\sum_{i=1}^{n} \ln x_{i}^{3} \\
& -\sum_{i=1}^{n} \frac{a \alpha \theta}{x_{i}^{2}}+(b-1) \sum_{i=1}^{n} \ln \left[1-e^{\frac{\theta a \alpha}{x_{i}^{2}}}\right] \ldots
\end{aligned}
$$

The MLE obtained by solving the above non-linear system of eqn. (6). In eqn. (6) we do not have the exact solution, from the large sample property of ML Estimates; MLE $\hat{\theta}$ can be treated as being

approximately normal with mean $\theta$ and variance covariance matrix equal to the inverse of the expected information matrix.

i.e., $\sqrt{n}(\hat{\theta}-\theta) \rightarrow N\left(0, n I^{-1}(\theta) . I(\theta)\right.$ is the information matrix then its inverse of matrix is $I^{-1}(\theta)$ provides the variances and covariance's. 
Ramakrishnan B et al. Determination of Hazard State of Non-Communicable Diseases Using Semi-Markov Model

$\widehat{a} \pm Z_{\frac{\alpha}{2}} \sqrt{I_{a a}^{-1}(\hat{\theta})}, \quad \hat{\alpha} \pm Z_{\frac{\alpha}{2}} \sqrt{I_{\alpha \alpha}^{-1}(\hat{\theta})}, \hat{b} \pm Z_{\frac{\alpha}{2}} \sqrt{I_{b b}^{-1}(\hat{\theta})}, \hat{\theta} \pm Z_{\frac{\alpha}{2}} \sqrt{I_{\theta \theta}^{-1}(\hat{\theta})} \ldots$

The significance providing by iterations as observed in equation (7), with likelihood functions as the ideal solution to the parameters.

Table-1, is a typical Markov chain state consistent to transition matrix $P$ with the interactive population size of region transition probabilities change from the first state observation, as observed in eqn. (3)

$$
\operatorname{Pij}(t)=\left[\begin{array}{cccc}
1-a & b & \alpha & \theta \\
\alpha & 1-b & \theta & a \\
b & \theta & 1-\alpha & a \\
\theta & \alpha & b & 1-\theta
\end{array}\right]
$$

Table 1. The transitions between the phases of the process occur at regular intervals.

\begin{tabular}{|c|c|c|c|}
\hline $\begin{array}{c}\text { Patients has } \\
\text { Hypertension }\end{array}$ & $\begin{array}{c}\text { Patients has } \\
\text { Heart } \\
\text { Diseases }\end{array}$ & $\begin{array}{c}\text { Patients has } \\
\text { Smoking Habits }\end{array}$ & $\begin{array}{c}\text { Patients } \\
\text { had a } \\
\text { Stroke }\end{array}$ \\
\hline 498 & 276 & 1674 & 249 \\
\hline 214 & 36 & 214 & 66 \\
\hline 36 & 138 & 138 & 27 \\
\hline 214 & 138 & 1674 & 249 \\
\hline 66 & 47 & 112 & \\
\hline
\end{tabular}

The rows of eqn. (8), signifies the present four states of the model use withdrawal and renormalization, of Stroke processes and long-term process, the columns represent the four statuses (S2, S3, S4 and S5) on the state. The records in the first row access the probabilities of hypertension will stay to stroke $(1-a)$ or leave (a), and thus move into the second state b. Following the first row, the second row provides probability an individual in $\mathrm{b}$ will be in the next observation, having heart diseases in state $(1-b)$. The third row gives the probability of smoking habits $(1-$ $\alpha)$ and forth state had a stroke process $(1-\theta)$. [13]

\section{Results and Discussion}

For the taken dataset [14], with the utilization of information factors like segment attributes and various sicknesses, the dataset might be used to foresee whether a patient is probably going to experience the ill effects of stroke. Every section in the dataset contains data about the patient that is pertinent to that segment.

The accompanying five state boundaries were set up for the model turn of events, as displayed in Figure-1, for the accompanying reasons:
The accompanying five state boundaries were set up for the model turn of events, as displayed in Figure-1, for the accompanying reasons:

S1: Patients Age and Gender

S2: Patients with Hypertension

S3: Patients with Heart Diseases

S4: Patients with Smoking Habits

S5: Patients with Stroke

\section{Figure - 1 A five-state model data from the Hepatitis $\mathrm{C}$ Prediction Dataset}

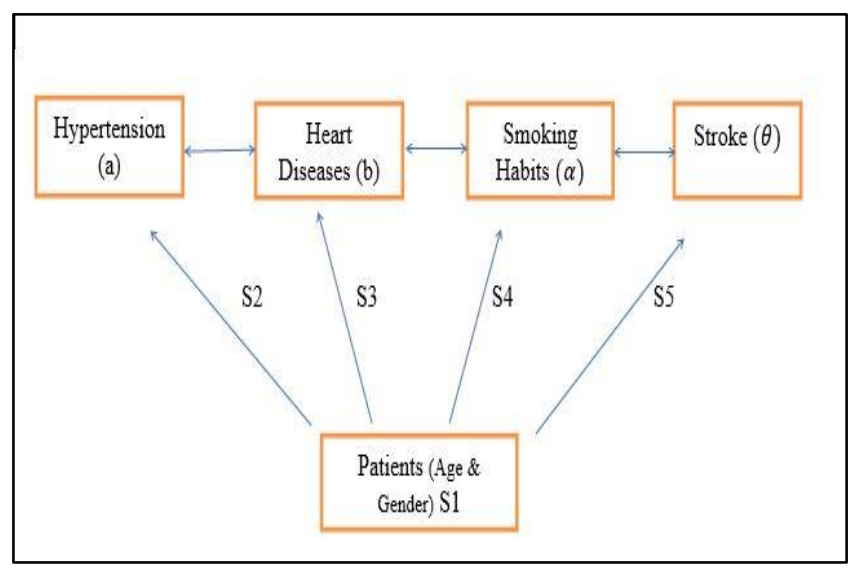

In the Assembled Realm, the Clinical Exploration Gathering Malignancy Family Appraisal Exploration (MRC CFAS) is an enormous size multi-focus longitudinal glance. [15]

The examinations, what began inside the late 1980s and covered a specialist example of thirteen 004 individuals from the more seasoned organization, transformed into intended to explore dementia and intellectual decrease inside the matured people. The realities have also been utilized to concentrate on various afflictions along with sadness [16] and actual debilitation [9], notwithstanding to view the solid energetic future [2] of the members. The meetings with people have been acted in extra of 46000 cases to far. There are more insights on the gander plan close by on the web (www.Cfas.Ac.United realm). To take a gander at getting more seasoned inside the more established people, the creators utilized a three-country variant with the conditions of "healthy," "records of stroke," and "death." The conditions of "refreshing," "history of stroke," and "death toll" have been totally addressed through change powers in a three-state model (country three).

In Figure-2, you could see an illustration of the multi-state model. It very well may be energizing to look how the amount of time that elapses following a stroke impacts the charge of downfall. We concentrate on a subset of the MRC CFAS data, explicitly records from the Newcastle place. This data set may be known as the MRC CFAS for the length of this paper. This subset conveys data on 2316 individuals who had been 65 years or more established at the time 
in their meeting, which occurred among 1991 and 2003. These individuals have been exposed to however much nine meetings throughout which they have been mentioned on the off chance that they had a stroke for the explanation that their past visit, and their age at the hour of the meetings changed into noted. Even after the conviction of the subsequent period, the exact dates of death are all things considered close by. At pattern, the people's stroke history became explored, and they gave measurements on their age (A), sexual orientation ( $\mathrm{G}$; 0 for women and 1 for folks), long periods of tutoring (E; zero for under 10 years and 1 for a considerable length of time or extra), and smoking distinction at 60 years old years (S; zero for non-smokers or ex-smokers and 1 for current individuals who smoke). By characterizing smoking along these lines, it's miles less potentially that people could give up due to disease.

After the age of 60, smoking conduct won't change. The yearly report on smoking-related direct and perspectives distributed in 2005 [6] saw that the people who smoke after the age of 65 years are the most un-plausible of all to need to stop, and the individuals who do wish to stop are significantly more liable to have accomplished so before the age of 65 years. People contrasted in expressions of the number of meetings they had and the measure of time they spent among interviews. Figures 2(a) and a couple of 2(b) portray the wide assortment of meetings finished through anyone, just as a dispersion of the time of follow-up spans, separately.

Figure - 2(a) Unmistakable information on the quantity of meetings per individual

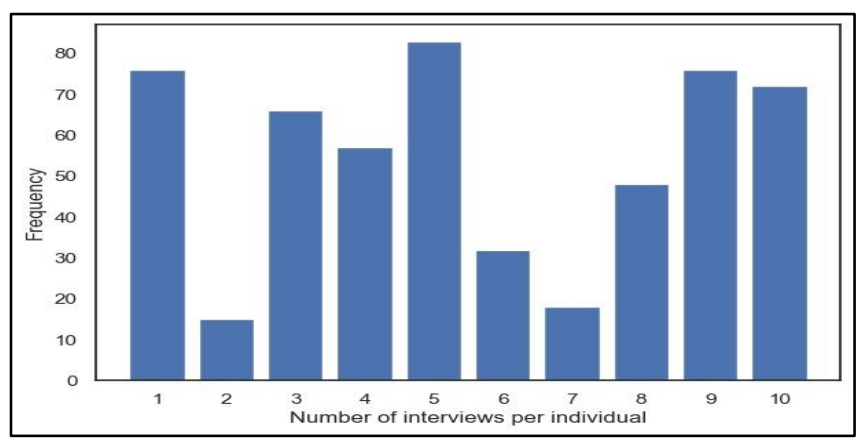

Figure - 2 (b) Unmistakable information on the length among meetings

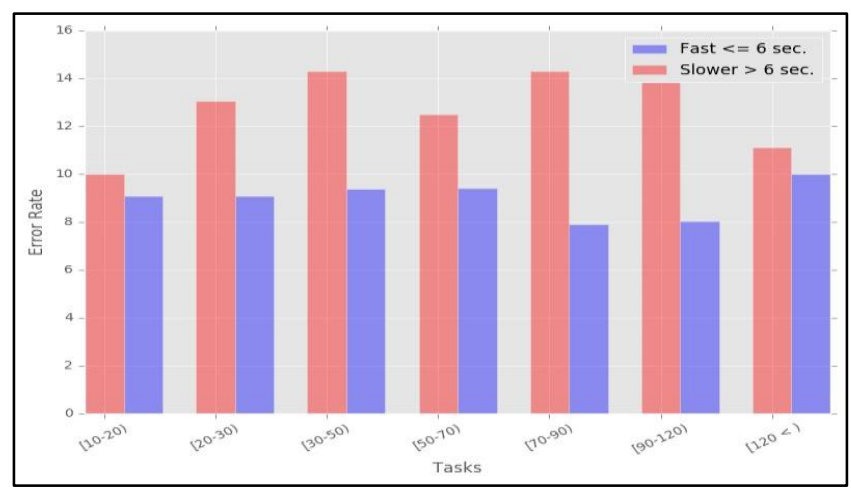

The standard length of notice up spans changed into years, and the middle wide assortment of meetings directed was with regards to member. Figure 2(c) portrays the circulation of time between the hour of the last meeting and the hour of destruction or appropriate control, whichever happens first.

Figure - 2(c) Unmistakable information on the time between the last meeting and either demise or control are likewise accessible

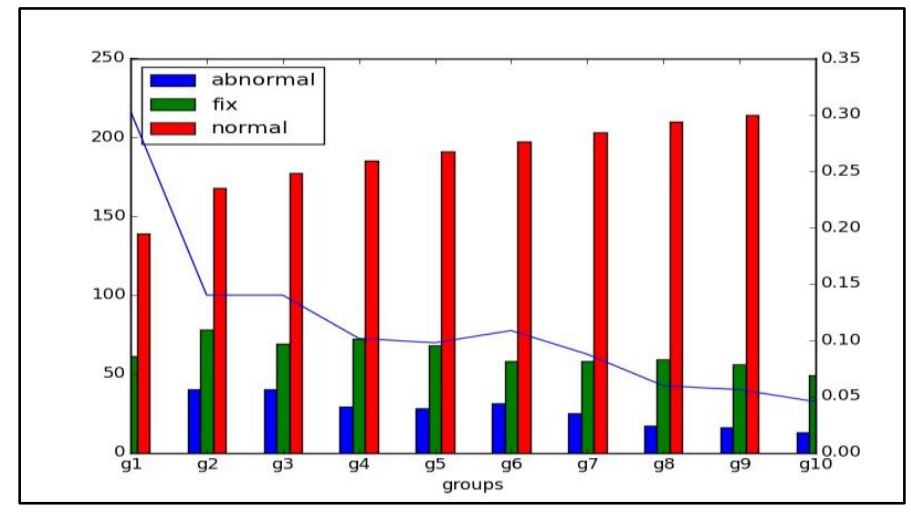

Frequencies of change are summed up from the dataset. The answers for the change probabilities $\mu_{-}(\mathrm{ij})(\mathrm{t})$ at time $t$ utilizing the calculation are gotten with S5 states: $\mathrm{T}=6178$, progress likelihood matric as given in Table-1.

Table-1 shows the recurrence dispersions of sets of progressive states saw in the records test. These frequencies identify with the number of times a person had an assertion in country I followed through an assertion in country $\mathrm{j}$ for every one of the 2 states $\mathrm{I}$ and $\mathrm{j}$ and for the entirety of individuals in the example. In light of the varieties inside the states' definitions, there have been no advances from country 2 to country 1 . An assortment of likely detectable examples of follow-up for each body inside the MRC CFAS longitudinal investigations have been perceived inside the notice. A person can, as an occurrence, be in advantageous wellbeing while the analyze begins off evolved however at that point go through a stroke inside the next years and pass on or stay alive while the examiner closures, or the individual in question can be in superb wellness however at that point experience a stroke and either pass on before the view closes or be legitimate controlled, depending on the cases. Also, if an individual is accounted for to have had a stroke toward the beginning of the exploration, it's miles conceivable that the person might live to tell the story or pass on before the conviction of the investigate.

Figure-3, 4, 5, 6 portray a graphical portrayal of those various examples, which can be delegated free examples A-F. In styles A, B, E, and F, it is recognized that a shift from country 1 to country 2 has taken region sometime. In any case, on account of examples C and D, the ways of life of oversight makes it hard to decide if or presently not this kind of shift has occurred. As a final product, there are capacity results. It is possible that an individual moved to realm 2 anyway became in no way, shape or form reported on this nation because of restriction, or that a 
Figure 3: Effect on Patients from State S1 to S2 Figure 4: Effect on Patients from State S1 to S3

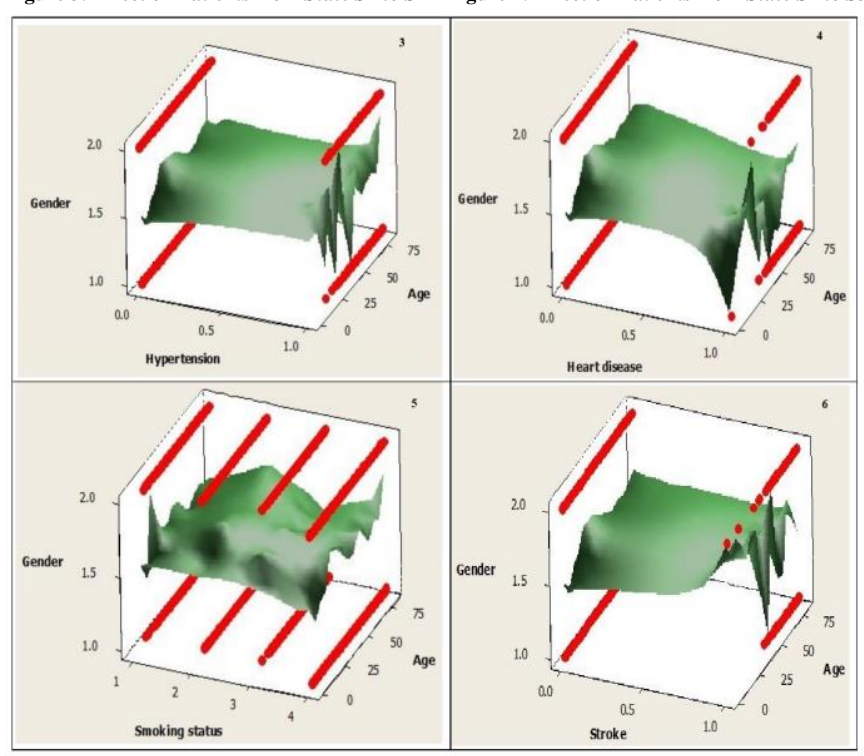

Figure 5: Effect on Patients from State S1 to S4 Figure 6: Effect on Patients from State S1 to S5

a person remained in realm 1 until the person passed on or the state turned out to be pleasantly blue-penciled. The estimated transition intensities for the Semi Markov Model are mentioned in Table-2.

Table: 2. The estimated transition intensities for the Semi Markov model

\begin{tabular}{|c|c|c|c|c|}
\hline $\begin{array}{c}\text { States } \\
\text { at time } \\
t_{i j}\end{array}$ & $\begin{array}{c}\text { Patients has } \\
\text { Hypertension }\end{array}$ & $\begin{array}{c}\text { Patients } \\
\text { has Heart } \\
\text { Diseases }\end{array}$ & $\begin{array}{c}\text { Patients } \\
\text { has } \\
\text { Smoking } \\
\text { Habits }\end{array}$ & $\begin{array}{c}\text { Patients } \\
\text { had a } \\
\text { Stroke }\end{array}$ \\
\hline State 1 & 0.485 & 0.435 & 0.439 & 0.354 \\
\hline State 2 & 0.208 & 0.056 & 0.056 & 0.095 \\
\hline State 3 & 0.035 & 0.217 & 0.037 & 0.038 \\
\hline State 4 & 0.207 & 0.217 & 0.439 & 0.159 \\
\hline State 5 & 0.065 & 0.075 & 0.029 & 0.354 \\
\hline
\end{tabular}

The Semi Markov transitional probabilities through KEIR for the effect of Patient's with age and gender determined by Patient's Hypertension, Patient's Heart Diseases, Patient's Smoking Habits and Patient's with stroke is examined. The threshold for each transition intensities are examined with the conditional probability that the patient will not survive after the time. Among the four nonCommunicable diseases the hazard for the Patient's having a Stroke is the first one to look for, as the survival of chance is minimal. The Patient having Stroke the next hazard was heart disease, then with Hypertension and Smoking habits was found.
At the time of the baseline study, the median age of the participants was 74 years. According to the research design, people above the age of 75 were over-sampled in order to obtain an equivalent number of participants as those aged $65-74$ years at the beginning of the study. Circling back to every member was booked to happen about like clockwork, as indicated by the review's plan. This present person's specific season of death has been set up. To represent the way that it is hard to build up the specific season of the progress from condition 1 to state-2, the information is exposed to separating on the left, right, and stretch tomahawks, individually. It is conceivable that exchanges from state- 1 to state- 2 were happened yet were not found preceding demise or right blue penciling toward the finish of the subsequent period, yet this has not been shown. Advances from state- 1 to state- 2 that happen before the review's beginning date are left edited; else, they are left shortened. For the situation that people are joined up with the exploration, advances from state- 1 to state- 2 that happen before the review's beginning date are left controlled. Prohibition from the examination might be set off by the passing of a member before to the review's initiation.

Among the five provinces of SMP, the Stroke state S5 is viewed as a retaining state; i.e., when a patient isn't truly in a functioning state, she/he won't ever be in the others states and rather remains there until the end of time. The S5 state stroke is classified Danger state and the others states S1, S2, S3 and S4 moderate states.

\section{Conclusion}

The developed Semi-Markov model is a best fit for nonCommunicable disease in the long run of patient's data. Through different Exponential family distribution, one can look at for further perfect fit of patient data, which is to be estimated. There are many more non-Communicable diseases which needs to be estimated in the goodness of fit in the future. This model can be an alternative method to estimate the effect of patient in survival analysis, where it will be effective in time consumption in medical field.

\section{Authors' contributions:}

BR, SKK, and MR: Conception and Study design; BR: Acquisition of Data; BR, SKK, MR: Data processing, Analysis and Interpretation of Data; All authors - BR, SKK, MR were drafting the article, revising it for intellectual content; All authors were checked and approved of the final version of the manuscript.

Here, BR - Balasubramaniam Ramakrishnan; SKK - Senthamarai Kannan; MR - Mahalakshmi Rajendran

\section{Source of funding: None}

Conflict of interest: None 


\section{References:}

1. Arboix A. Cardiovascular risk factors for acute stroke: Risk profiles in the different subtypes of ischemic stroke. World J Clin Cases 2015; 3(5):418. PMID: 25984516

2. James PA, Oparil S, Carter B L, PharmD, Cushman W C, Himmelfarb C D, et al. Evidence-based guideline for the management of high blood pressure in adults: Report from the panel members appointed to the Eighth Joint National Committee (JNC 8). JAMA 2014;311(5):507-520. DOI: 10.1001/jama.2013.284427

3. Janssen J, Manca R. Numerical solution of non-homogenous SemiMarko processes in Transient case. Methodology and Computing in Applied Probability 2001;3:271-279. DOI: 10.1023/A:1013719007075

4. The Global Burden of Stroke. Available from: http://www.who.int/cardiovascular_diseases/en/cvd_atlas_15_bur den_stroke.pdf?ua=1 [Accessed on: 24 August 2021]

5. Pilkington PA, Gray S, Gilmore AB. Health impacts of exposure to second hand smoke (SHS) amongst a highly exposed workforce: survey of London casino workers. BMC Public Health 2007;7(1):18. DOI: $10.1186 / 1471-2458-7-257$

6. Port S, Demer L, Jennrich R, Walter D, Garfinkel A. Systolic blood pressure and mortality. Lancet 2000;355:175-180. DOI: 10.1016/S0140-6736(99)07051-8

7. Staessen JA, Gasowski J, Wang JiG, Thijs L, Den Hond E, Boissel JP, et al. Risks of untreated and treated isolated systolic hypertension in the elderly: meta-analysis of outcome trials. The Lancet 2000;355:865-872. PMID: 10752701

8. Human Wellbeing advancement Available from: https://www.who.int/westernpacific/health-topics/healthpromotion [Accessed on: 12 August 2021]

9. Keage HAD, Matthews FE, Yip A, Gao L, McCracken C, McKeith IG, et al. MRC Cognitive Function and Ageing Study. APOE and ACE polymorphisms and dementia risk in the older population over prolonged follow-up: 10 years of incidence in the MRC CFA study. Age Ageing 2010;39(1):104-111. PMID: 19939808

10. Johnson, K. C, Whelton P K, Cushman W C, Cutler J A, Evans G $\mathrm{W}$, Snyder J K, et al. Blood pressure measurement in SPRINT (systolic blood pressure intervention trial). Hypertension 2018; 71(5):848-857. PMID: 29531173

11. Kapetanakis V, Matthews F E, Hout A. A semi-Markov model for stroke with piecewise-constant hazards in the presence of left, right and interval censoring. Statistics in Medicine 2012;32:697-713. PMID: 22903796

12. Meisel K, Silver B. The importance of stroke units. Medicine and Health, Rhode Island 2011;94(12):376-377. PMID: 22409131

13. McDougall FA, Kvaal K, Matthews FE, Paykel E, Jones PB, Dewey ME, et al. Prevalence of depression in older people in England and Wales: the MRC CFA study. Psychological Medicine 2007;37(12):1787-1795. DOI:_10.1017/S0033291707000372

14. The data used for the study. Available from: http://archive.ics.uci.edu/ml/datasets/HCV+data [Accessed on: 20 August 2021]

Publish your research articles with International Journal of Medical Sciences and Nursing Research Website: http://ijmsnr.com/
15. Melzer D, McWilliams B, C. Brayne C, Johnson T, Bond J. Socioeconomic status and the expectation of disability in old age: estimates for England. J Epidemiol community Health 2000;54:286-292. PMID: 10827911

16. Ul Haq MA. Kumaraswamy Exponentiated Inverse Rayleigh Distribution. Mathematical Theory and Modeling 2016;6:93104. 